Conclusion: Although patients with active RA and inadequate response to MTX have different therapeutic combination of biologics or small molecules options, the best relative efficacy in terms of ACR50 response after 24 weeks of treatment is for upadacitinib $15 \mathrm{mg} / \mathrm{day}$.

REFERENCES:

[1] Smolen JS, et al. Annals of the Rheumatic Diseases 2020;79:685-699.

[2] Combe B, Lukas C. Joint Bone Spine, 2020,105004.

[3] Caporali R, et al. Biomed Res Int. 2018 Sep 9;2018:3878953.

Disclosure of Interests: Fabio Cacciapaglia Speakers bureau: Roche, Pfizer, Eli Lilly, MSD, UCB, BMS, Abbvie, Vincenzo Venerito: None declared, Stefano Stano: None declared, Marco Fornaro: None declared, Giuseppe Lopalco Speakers bureau: Celgene, BMS, Abbvie, Novartis, Florenzo lannone Speakers bureau: Roche, Pfizer, Eli Lilly, MSD, UCB, BMS, Abbvie, Novartis, Celgene DOI: 10.1136/annrheumdis-2021-eular.3073

\section{POS0632 THE LONGITUDINAL ASSOCIATIONS OF METHOTREXATE AND BIOLOGIC USE ON HOSPITAL ADMISSION FOR RHEUMATOID ARTHRITIS PATIENTS IN WESTERN AUSTRALIA POPULATION (1995- 2014)}

K. Almutairi ${ }^{1}$, J. Nossent ${ }^{1}$, D. Preen ${ }^{2}$, H. Keen ${ }^{1}$, C. Inderjeeth ${ }^{1} .{ }^{1}$ The University of Western Australia, School of Medicine, Perth, Australia; ${ }^{2}$ The University of Western Australia, School of Population and Global Health, Perth, Australia

Background: Rheumatoid arthritis (RA) carries a substantial burden for patients and society in terms of morbidity, enduring disability, and costs [1]. The Australian Pharmaceutical Benefits Scheme (PBS) has subsidised biological disease-modifying anti-rheumatic drugs (B-DMARDs) since 2003 [2].

Objectives: We examined the impact of B-DMARDs availability on RA hospitalisation rate in the Western Australia (WA) population pre- and post- B-DMARDs introduction to the PBS (1995-2002 and 2003-2014).

Methods: Population PBS dispensing data for WA of DMARD were obtained and converted to defined daily doses (DDD)/1000 population/day using the WA population census. RA inpatient records were extracted from the WA Hospital Morbidity Data Collection using ICD-9 codes 714 and ICD-10 codes M05.00-M06.99). Principal component analysis (PCA) was applied to determine the relationship between DMARDs use and RA hospital admission rates.

Results: There was a total of 17,125 patients who had 50,353 admissions with a diagnostic code for RA during the study period. DMARD use for RA rose from 1.45 to 3.19 DDD/1000 population/day over 1995-2014 (Figure 1). In 1995-2002, the number of RA admissions fell from 7.9 to 2.6 per 1000 hospital separations, then dropped further from 2.9 to 1.9 per 1000 hospital separations in 2003-2014. Based on PCA analysis, conventional DMARDs (methotrexate) and B-DMARDs dispensing had an inverse association with hospital admissions for RA.

Conclusion: The increased availability of conventional and biological DMARDs for RA was associated with a significant decline in hospital admissions for RA patients in WA.

REFERENCES:

[1] Boonen A, Severens JL (2011) The burden of illness of rheumatoid arthritis. Clin Rheumatol 30:3-8.

[2] Medicare Australia (2020) Pharmaceutical Benefits Schedule statistics. http://medicarestatistics.humanservices.gov.au/statistics/pbs_item.jsp.

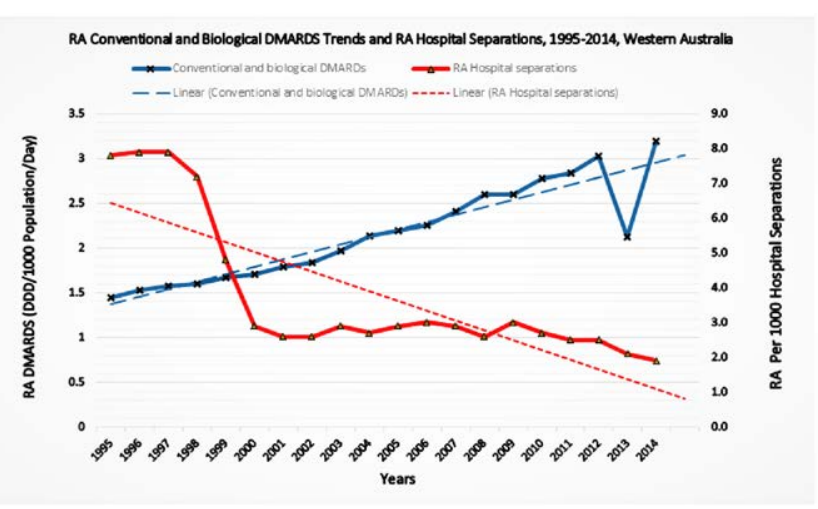

Figure 1. The hospital separations and total drugs use patterns of RA in 1995-2014 in Western Australia.

Acknowledgements: Supported by an Australian Government Research Training Program PhD Scholarship at the University of Western Australia.

Disclosure of Interests: Khalid Almutairi: None declared, Johannes Nossent Speakers bureau: Janssen, David Preen: None declared, Helen Keen Speakers bureau: Pfizer Australia, Abbvie Australia, Charles Inderjeeth Speakers bureau: bureau: Eli Lilly DOI: 10.1136/annrheumdis-2021-eular.3230

\section{POS0633 DURATION OF STARTING BDMARDS ARE ALMOST 3 TIMES LONGER IN RA PATIENTS THAN PSA PATIENTS: HUR-BIO REAL LIFE RESULTS}

G. K. Yardımcı ${ }^{1}$, B. Farisoğulları ${ }^{1}$, E. C. Bolek ${ }^{1}$, E. Bilgin ${ }^{1}$, E. Duran ${ }^{1}$, G. Ayan ${ }^{1}$ Z. Özsoy ${ }^{1}$, G. Sandal Uzun ${ }^{1}$, L. Kılıç ${ }^{1}$, A. Akdoğann', O. Karadag ${ }^{1}$, Ş. A. Bilgen ${ }^{1}$, S. Kiraz ${ }^{1}$, A. İ. Ertenli ${ }^{1}$, U. Kalyoncu ${ }^{1} .{ }^{1}$ Faculty of Medicine; Hacettepe University, Rheumatology, Ankara, Turkey

Background: Before using biological DMARDs, EULAR suggests the use of synthetic DMARDs (especially methotrexate) for RA and PsA [1-2].

Objectives: It was aimed to evaluate the differences of disease duration and csDMARDs till first bDMARD in RA and PsA patients.

Methods: HUR-BIO (Hacettepe University Biologic Registry) is a prospective, single center database of biological treatments since 2005 and to date 2070 RA and 520 PsA patients have been recorded. Demographic, clinical and laboratory data before bDMARDs of the patients were noted. When investigating the differences between groups, the effects of gender, age and disease duration wereadjusted using two-way ANOVA and ANCOVA tests. The selection was made for the gender, age and for indifference of the relevant groups by using prospensity score matching

Results: We incuded $481 \mathrm{RA}$, and $482 \mathrm{PsA}$ age and gender matched patients in the study. Age, gender and disease duration information were given in the Table 1. $72.8 \%$ of the RA patients were RF or anti-CCP positive. Overall, $56.3,100 \%$ of the RA, and PsA patients first biologic therapies were anti-TNFs, respectively. All RA patients started with csDMARDs before bDMARD treatments, whereas 450 of $482(93.4 \%)$ PsA patients. Methotrexate was the anchor csDMARD for both diseases. RA patients more frequently used all csDMARDs included methotrexate, leflunomide, sulphasalazine hydroxychloroquine and corticosteroids as well. Median disease duration till bDMARD treatments in RA and PsA patients were 55 and 18.5 months respectively $(p<0.001)$ (Table 1$)$.

Table 1. Demographic characteristics and csDMARDs before first bDMARD

\begin{tabular}{|c|c|c|c|c|}
\hline & & $R A(n=481)$ & PsA $(n=482)$ & $P$ value \\
\hline Female, $\mathrm{n}(\%)$ & & $319(66.3)$ & $332(68.9)$ & 0.218 \\
\hline Age, years (mean $\pm S D)$ & & $48.2 \pm 13.5$ & $47.4 \pm 12.2$ & 0.332 \\
\hline Disease duration, years* ${ }^{\star}$ & & $10(6-16)$ & $7(3-12)$ & 0.000 \\
\hline $\begin{array}{l}\text { Symptom duration before diagno- } \\
\text { sis, years }{ }^{*}\end{array}$ & & $0(0-1)$ & $1(0-4)$ & $0.000^{*}$ \\
\hline $\begin{array}{l}\text { The period of time between diag- } \\
\text { nosis and bDMARD initiation, } \\
\text { months }{ }^{*}\end{array}$ & & $55(24-115)$ & $18.5(8-58)$ & $0.000^{*}$ \\
\hline $\begin{array}{l}\text { The period of time between symp- } \\
\text { toms and bDMARD initiation, } \\
\text { months }{ }^{*}\end{array}$ & & $70(35-151)$ & $48(20-124)$ & $0.000^{*}$ \\
\hline \multirow[t]{2}{*}{ Methotrexate } & Ever $\mathrm{n}(\%)$ & $400(83.3)$ & $373(77.5)$ & 0.015 \\
\hline & $\begin{array}{l}\text { Just before } \\
\text { bDMARD initia- } \\
\text { tion } n(\%)\end{array}$ & $251(52.2)$ & $230(47.7)$ & 0.093 \\
\hline Hydroxychloroquine sulfate & $\begin{array}{l}\text { Ever n (\%) } \\
\text { Just before } \\
\text { bDMARD initia- } \\
\text { tion } n(\%)\end{array}$ & $\begin{array}{l}292(60.8) \\
262(54.5)\end{array}$ & $\begin{array}{l}170(35.3) \\
99(20.5)\end{array}$ & $\begin{array}{l}0.000^{*} \\
0.000^{*}\end{array}$ \\
\hline Leflunomide & $\begin{array}{c}\text { Ever } \mathrm{n}(\%) \\
\text { Just before } \\
\text { bDMARD initia- } \\
\text { tion } \mathrm{n}(\%)\end{array}$ & $\begin{array}{l}237(49.4) \\
160(33.3)\end{array}$ & $\begin{array}{l}129(26.8) \\
96(19.9)\end{array}$ & $\begin{array}{l}0.000^{*} \\
0.000^{*}\end{array}$ \\
\hline Sulphasalazine & $\begin{array}{l}\text { Ever } \mathrm{n}(\%) \\
\text { Just before } \\
\text { bDMARD initia- } \\
\text { tion } \mathrm{n}(\%)\end{array}$ & $\begin{array}{l}353(73.5) \\
156(32.4)\end{array}$ & $\begin{array}{l}265(55.1) \\
146(30.3)\end{array}$ & $\begin{array}{l}0.000^{*} \\
0.259^{*}\end{array}$ \\
\hline Corticosteroids & $\begin{array}{l}\text { Ever } \mathrm{n}(\%) \\
\text { Just before } \\
\text { bDMARD initia- } \\
\text { tion } \mathrm{n}(\%)\end{array}$ & $\begin{array}{l}419(87.3) \\
335(69.6)\end{array}$ & $\begin{array}{l}281(58.4) \\
187(38.8)\end{array}$ & $\begin{array}{l}0.000^{*} \\
0.000^{*}\end{array}$ \\
\hline
\end{tabular}

¥Median (IQR)

Conclusion: According to HUR-BIO real life data, for inflammatory arthritis patients who started bDMARDs, the periods of time between diagnosis and bDMARDs were more reasonable (18 months) in PsA patients than RA patient's periods which were approximately three times longer. RA patients were used much more and longer duration of csDMARDs. This explicit distinction may be explained by synthetic DMARDs on activity differences between the RA and PsA.

REFERENCES:

[1] Gossec, L., et al., EULAR recommendations for the management of psoriatic arthritis with pharmacological therapies: 2019 update. Ann Rheum Dis, 2020. 79(6): p. 700-712.

[2] Smolen, J.S., et al., EULAR recommendations for the management of rheu matoid arthritis with synthetic and biological disease-modifying antirheumatic drugs: 2019 update. Ann Rheum Dis, 2020. 79(6): p. 685-699. 
Disclosure of Interests: None declared

DOI: 10.1136/annrheumdis-2021-eular.3283

\section{POS0634 DO BIOLOGICS IMPROVE FATIGUE IN PATIENTS WITH RHEUMATOID ARTHRITIS?}

A. Fazaa ${ }^{1}$, H. Boussaa ${ }^{1}$, K. Ouenniche ${ }^{1}$, S. Miladi ${ }^{1}$, M. Sellami ${ }^{1}$, L. Souabni ${ }^{1}$, S. Kassab ${ }^{1}$, S. Chekili ${ }^{1}$, K. Ben Abdelghani ${ }^{1}$, A. Laatar ${ }^{1} .{ }^{1}$ Mongi Slim University Hospital, Rheumatology, Sidi Daoud, Tunisia

Background: Fatigue is a significant issue in rheumatoid arthritis (RA) with no accepted evidence-based management guidelines. Several studies suggested that biologic Disease Modifying Anti-Rheumatic Drugs (bDMARDs) have a direct role on fatigue in RA. Objectives: This study aimed to compare fatigue between patients treated with bDMARDs and conventional synthetic Disease Modifying Anti-Rheumatic Drugs (cs DMARDs)

Methods: We conducted a longitudinal study including patients with RA (ACR/ EULAR 2010). Patients with other acute or chronic diseases that may induce fatigue (such as cancer, infection or depression) were excluded. Demographic data and the following disease-related parameters were collected: pain Visual Analog Scale (VAS), Global Patient Assessment (GPA), tender joint count (TJC), swollen joint count (SJC), Erythrocyte Sedimentation Rate (ESR), C Protein Reactive (CRP), Disease Activity Score 28 (DAS28), Health Assessment Questionnaire (HAQ) and DMARDs used. Fatigue was assessed at baseline (T0), at 6 months (T6) and at 12months (T12) using the Functional Assessment of Chronic Illness Therapy - Fatigue (FACIT-F) which is a short 13-item questionnaire validated in RA. The score FACIT-F ranges between 0 and 52. Fatigue was considered mild if the FACIT-F score was $\geq 40$, moderate if $20 \leq F A C I T-F<40$ and severe if $0 \leq F A C I T-F<20$. A p value inferior to 0.05 was considered significant.

Results: We included 100 RA patients ( 84 women and 16 men) with a mean age of $49.5 \pm 10$ years old [18-65]. The mean disease duration was 87.3 months [1-360]. The mean pain VAS was $49 \mathrm{~cm}$ [0-100] and the mean GPA was $47.8 \mathrm{~cm}$ [0-100]. The mean TJC and SJC were 5.3 [0-36] and 1 [0-9] respectively. The mean levels of ESR and CRP were $38.1 \mathrm{~mm}$ [10-120] and $10.8 \mathrm{mg} / \mathrm{l}$ [2-61] respectively. The mean DAS28 ESR was 3.68 [1.90-8.33] and the mean HAQ score was 0.90 [0-2.75] Eighty-three percent of patients used csDMARDs: Methotrexate $(n=96)$, sulphasalazine $(n=28)$, leflunomide $(n=21)$, and hydroxychloroquine $(n=12)$. bDMARDs were prescribed in $17 \%$ of patients: Rituximab $(n=10)$, Infliximab $(n=9)$, and Etanercept $(n=5)$. At baseline, the mean FACIT-F score was 27.1 [0-51]. Moderate fatigue was noted in $57 \%$ of cases and severe fatigue in $26 \%$ of cases. Patients on csDMARDs had a lower FACIT-F score when compared to patients on bDMARDs (26.89 versus $28.41)$, but the difference was not statistically significant $(p=0.630)$

The mean FACIT-F score was 27.41 in bDMARDs patients versus 29.80 in csDMARDs patients $(p=0.497)$ at $T 6$, and 32.35 versus 33.65 respectively at $T 12(p=0.695)$.

The mean delta FACIT-F was 2.18 in bDMARDs patiens versus 2.73 in csDMARDs patients between T6 and T0 ( $p=0.815)$, and 3.94 versus 7.2 respectively between $\mathrm{T} 12$ and T0 $(\mathrm{p}=0.807)$.

When considering all patients, a significant positive correlation was noted between delta FACIT-F and delta DAS28 at T6 $(r=0.418, p<0.001)$ and at T12 $(r=0.338, p<0.001)$.

Conclusion: RA patients treated with bDMARDs didn't show significant improvement of fatigue in comparison with those treated with csDMARDs. Further studies are needed to determine if biologics improve fatigue, and whether the improvement results from a direct action on fatigue or indirectly through reduction in disease activity. Disclosure of Interests: None declared

DOI: 10.1136/annrheumdis-2021-eular.3351

\section{POS0635 1 COMPARING THE ULTRASONOGRAPHIC EVALUATION IN PATIENTS WITH JAPANESE RHEUMATOID ARTHRITIS BETWEEN BARICITINIB AND TNF ANTAGONIST THERAPY}

Y. Kanayama ${ }^{1}$, A. Nagata ${ }^{2}$, M. Shimotake ${ }^{2}$, F. Miyachi ${ }^{2}$, K. Fujita ${ }^{2}$, M. Koyama ${ }^{2}$, S. Uno ${ }^{2} .{ }^{1}$ Toyota Kosei Hospital, Orthopedic Surgery and Rheumatology, Toyota, Japan; ${ }^{2}$ Toyota Kosei Hospital, Clinical Technology, Toyota, Japan

Background: Baricitinib (BAR) and TNF antagonist are the important therapeutic agent for the treatment of rheumatoid arthritis. However there is still few studies of improvement of ultrasonographic findings in RA treated comparison with BAR and TNF.

Objectives: To evaluate the clinical efficacy of BAR and TNF therapy patients with rheumatoid arthritis (RA) using ultrasonography (US).

Methods: Participants comprised 16 and 45 Japanese RA patients who had recently received BAR and TNF. All patients with a diagnosis of RA according to the 2010 ACR/EULAR criteria. Patients underwent clinical and laboratory assessments every 4 weeks from baseline to 24 weeks, and US assessments at baseline, 4 , 12 and 24 weeks. Gray scale (GS) and power doppler (PD) signals were scored using a semi-quantitative scale from 0 to 3 at $26(0-78)$ synovial sites (22 joints) in the following joints: bilateral first to fifth metacarpopharangeal (MCP) joints (dorsal recess); first interphalangeal (IP) and second to fifth proximal interphalangeal (PIP) (dorsal recess) joints; and the wrists (dorsal radial, median and ulnar). We evaluated the improvement of GS and PD score from baseline to week 24.

Results: In the patients receiving BAR $(n=16)$ and TNF $(n=45)$, the mean age was 55.9 vs 54.6 years old $(p=0.682)$, disease duration was 10.2 vs 6.1 years $(p=0.094)$ the rate of MTX use was $75 \%$ vs $89 \%(p=346)$, the mean MTX dose was 9.3 vs $10.2 \mathrm{mg} / \mathrm{w}(\mathrm{p}=0.443)$, the rate of ACPA positive was $94 \%$ vs $82 \%(p=0.476)$, DAS28ESR was 4.25 vs 4.61 ( $p=0.289)$, CDAl was 15.8 vs $18.5(p=0.210)$, GS score was 21.6 vs $16.3(p=0.436)$ and PD score was 15.0 vs $9.5(p=0.260)$. The degree of improvement respective changes in GS and PD score after 4, 12 and 24 weeks were as follows: GS: -7.2 vs -3.7 ( $p=0.268)$ and PD: -7.6 vs $-2.3(p=0.158)$ after 4 weeks, GS: -10.9 vs $-5.0(p=0.161)$ and PD: -9.2 vs $-3.8(p=0.049)$ after 12 weeks, GS: -12.9 vs $-6.1(p=0.485)$ and PD: -11.3 vs $-5.7(p=0.062)$ after 24 weeks between BAR and TNF (Fig.1, 2). Next, The improvement rate of respective changes in GS and PD score after 4,12 and 24 weeks were as follows: GS: $-23.8 \%$ vs $-11.6 \%(p=0.580)$ and PD: $-30.3 \%$ vs $-16.5 \%(p=0.343)$ after 4 weeks, GS: $-39.6 \%$ vs $-15.6 \%(p=0.129)$ and PD: $-47.1 \%$ vs $-30.8 \%(p=0.210)$ after 12 weeks, GS: $-52.2 \%$ vs $-22.2 \%(p=0.248)$ and PD: $-77.1 \%$ vs $-50.1 \%(p=0.048)$ after 24 weeks between BAR and TNF.

Conclusion: The present study provides evidence supporting both the BAR and TNF therapy showed improvement effect over time, but in a comparison between BAR and TNF, the PD score of BAR showed a siginificant improvement effect compared to TNF at 12 and 24 weeks. It was suggeted that BAR may improve inflammatory synovitis earlier compared to TNF

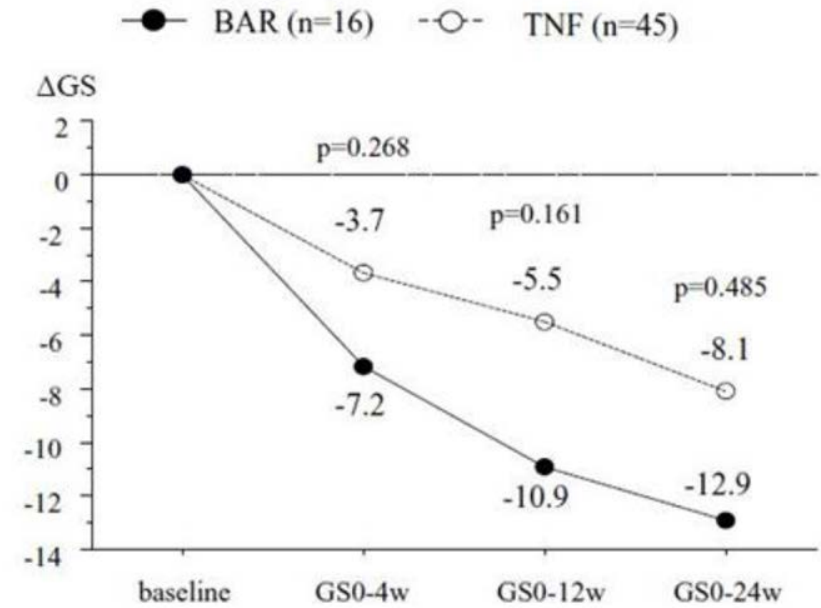

Figure 1: The degree of improvement respective changesin GS score from baseline to Week 24 between BAR and TNF patients

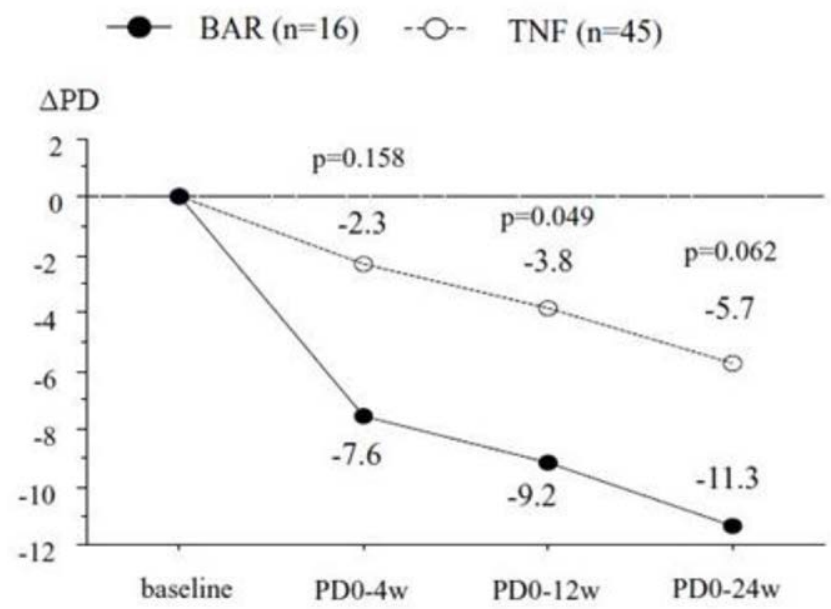

Figure 2 : The degree of improvement respective changesin PD score from baseline to Week 24 between BAR and TNF patients

Disclosure of Interests: None declared

DOI: 10.1136/annrheumdis-2021-eular.3483 